\title{
Development of sports psychiatry in the United States and internationally
}

\author{
Ira D. Glick', Todd Stull ${ }^{2}$, and Alan Currie ${ }^{3}$ \\ 1 Department of Psychiatry and Behavioral Sciences, Stanford University School of Medicine, Stanford, CA, USA \\ 2 Department of Psychiatry and Neuroscience, School of Medicine, University of California Riverside, Riverside, CA, USA \\ 3 Wolfson Research Centre, Regional Affective Disorders Service, Campus for Ageing and Vitality, Cumbria, Northumberland, \\ Tyne and Wear NHS Foundation Trust, Newcastle, United Kingdom
}

We are honored to describe the development of Sports Psychiatry in the USA and globally for the first issue of Sports Psychiatry. Our aim is to give 1) a succinct overview of the field focusing on its history, maturation and current status, 2) the role of the sports psychiatrist and 3) developments internationally.

In the last three decades the literature has detailed founding objectives, definitions of what a sport psychiatrist is and what a sport psychiatrist does - plus some of the reasons why they have been excluded from "Sports Medicine" [1, 2]. We now think of the range of sports psychiatry as a medical, psychiatric-psychologic-mental health discipline with a neuroscience and integrated medication and psychotherapeutic foundation. The literature details diagnosis and treatment for amateur and elite athletes, youth and adult sports, men and women, teams (and their support staff, trainers, and coaches) and leagues in both individual and team sports. It describes a) models of intervention, b) the range of treatments (psychotherapy, medication, skills and performance interventions), c) range of treatments for symptoms, disorders, and diseases - as well as d) transitions like retirement, problems like cheating, and the evolution of the field to achieving a full role as part of the Sports Medicine team [1, 2, 3].

\section{Development of the sports psychiatry field in the USA}

In the early 1990s, a half-dozen psychiatrists working with athletes over the USA began to work together and founded the International Society of Sports Psychiatry (ISSP). The group defined the field, its objectives, and its evolution over the next three decades [2]. Initially, it was defined as "sports psychiatry is the application of the principles of, and the function of psychiatry to the world of sports." As such, the group aimed to move from its position outside of the sports medicine field, as they had been viewed as working in "mental health", rather than "physical health", i.e. the brain. The emphasis was to work with the "brain and mind" in relation to the issues, problems, symptoms, disorders and diseases associated with the world of sports [4]. The Sports Psychiatrist is now increasingly viewed as a physician who diagnoses and treats:

- problems, symptoms or disorders associated with an athlete,

- or with the athlete's family/significant others,

- or with the athlete's team,

- or with the athlete's sport, e.g. TBI in football or doping in cycling in order to bring the athlete to optimal health and performance.

As the role of sports psychiatry has expanded, its clinical repertoire has increasingly incorporated performanceenhancing methods. Sports psychiatry also has become involved with the broader range of the field with such topics such as performance-enhancing substances (PESs), substance use disorders, concussion/TBI and cheating [3].

In 2018, the International Olympic Committee (IOC) has for the first time convened a consensus meeting on "mental health in elite athletes", bringing together experts from a variety of medical and other fields [5, 6]. There has been much new activity in the professional sports leagues in setting up a network of "mental health" providers working with teams [7]. 


\section{Role of the sports psychiatrist [8]}

A sports psychiatrist is a fully trained physician, who has attained specialty postgraduate training and experience in psychiatric and substance evaluations; they are trained in the treatment of emotional, cognitive, and behavioral symptoms seen in athletes. Sports psychiatrists have a broad range and depth of training and can provide a biopsychosocial and cultural formulation to care and deliver a full range of treatment options. The medical training of a sports psychiatrist provides a unique conduit between sports medicine and mental health providers and other members of the integrated sports team (IST). A sports psychiatrist often operates with a consultation and team (community) model to actively provide or lead in implementing shared care and management of treatment goals with other clinicians. Skills are applied, adapted, and contextualized specifically for developmental stages and settings ranging from beginning to high-performance sports environments. The primary role of the psychiatrist is help - provide clinical psychiatric care to the athletic community that supports the health, wellbeing and performance of athletes and teams.

Sports psychiatrists benefit from having a working knowledge of the roles of various individuals within the IST. The IST is designed to work with individual athletes and teams within a given sport. Each sport has a unique set of requirements needed to excel and perform optimally. The psychiatrist is best equipped to have a working knowledge of the multidimensional nature of the athlete's life and the roles, responsibilities, terminology, and understanding of sports and how each individual or area functions. The sports psychiatrist needs to have a strategy to communicate within the IST and effectively implement recommendations.

The sports psychiatrists can help a team/organization create a list of screening tools to use in identifying those athletes who may need further evaluation for a substance use or other psychiatric disorder. A part of this process ideally should include education to create an understanding of mental health and substance-related issues and how they are identified, evaluated, treated, and managed.

Finally, the treatment approach should always start with a diagnostic evaluation and workup to rule out medical causes for psychiatric symptoms and disorders. An integrated multidisciplinary treatment approach that includes psychotherapy coupled with psychopharmacotherapy, if indicated, should follow.

\section{The international perspective}

\section{$[9,10,11,12]$}

Outside of the USA, there has been significant growth in sport psychiatry in the last two decades with many in the field looking to the ISSP for support, guidance, and leadership. In the early 2000s for example, sports psychiatrists in central Europe began to collaborate and to share ideas in the science and practice of sports psychiatry and to publish in the field [10]. Later, in 2016 in the United Kingdom, a sport and exercise psychiatry group was formed and now has over 1000 members, several of whom have gone on to accredit themselves with the ISSP certificate in sports psychiatry. This group advocates not only for improved mental health within sport, but also for the incorporation of sport, exercise, and physical activity into mainstream mental healthcare to improve the mental health of everyone. The UK group meets twice per year for a scientific and clinical conference and its members have published two books while contributing to many others $[9,10,11]$.

In 2019, the English Institute of Sport (EIS) appointed two psychiatrists to a panel to advise on policy and practice in high performance sport and to support the IST. There has been much collaboration between the EIS and colleagues in Australia who provide mental healthcare to the Australian Institute of Sport (AIS) and where there is growing acceptance of the value of the psychiatrist on the IST in many sports. There are many other examples from around the world, for example Brazil where the seeds sewn by the ISSP in the early 1990s have scattered and flourished as we move towards a time where athlete mental healthcare is on a par with physical healthcare.

\section{Summary and conclusion}

Over the past three decades the Sports Psychiatry field has grown to take its place as an integral part of Sports Medicine. Teams of the old and young, for men and especially for women, have understood the necessity of having a sports psychiatrist as part of the medical team. As such, there is now increasing development of both research on the effectiveness of treatment as well as to determine the basic epidemiology of the field, e.g. incidence and prevalence associated with athletes.

Problems for the field include overcoming stigma associated with psychiatric illness, ensuring that our specialists are adequately trained (ISSP offers certification in Sports Psychiatry), and encouraging controlled research in order to have an evidence base for what we do.

Countries including Germany, Switzerland, Brazil, Canada, United Kingdom, Australia, and New Zealand, as well as in the USA, have started to connect their physicians and their organizations to advance the field.

The future is expanding globally with increasing focus on the "mental and physical health" of athletes before, during, and after their careers on and off the field. We view the expanding involvement of Sports Psychiatry into Sports 
Medicine as a very positive and a gradually increasing evolution [13].

\section{References}

1. Begel D. An overview of sports psychiatry. Am J Psychiatry. 1992;49:606-614.

2. Begel D, Burton RW (Eds). Sport psychiatry. New York: Norton and Company; 2000.

3. Glick ID, Castaldelli-Maia JM (Eds.). Special issue: Sports psychiatry 2016: A developing field. Int Rev Psychiatry 2016; 28(6).

4. Glick ID, Kamis D, Stull T. The ISSP Manual of Sports Psychiatry: From the International Society of Sports Psychiatry. New York: Rutledge Press; 2018.

5. Reardon CL, Hainline B, Aron CM, Baron D, Baum AL, Bindra A. et al. Mental health in the elite athletes: International Olympic Committee Consensus Statement. Br J Sports Med. 2019;53: 667-699.

6. Glick ID, Stillman MA, Reardon CL, Ritvo EC. Managing psychiatric issues in elite athletes. $J$ Clin Psychiatry. 2012:73;640-644.

7. McDuff DR, Garvin M. Working with sports organizations and teams. Int Rev Psychiatry. 2016;28:595-605.

8. Stull T, Glick ID, Kamis D. The role of a sport psychiatrist on the sports medicine team, circa 2021. Psychiatr Clin N Amer. 2021;44:333-345.
9. Currie A, Owens B (Eds). Sports Psychiatry. Oxford: Oxford University Press.

10. Markser VZ. Sport psychiatry and psychotherapy. Mental strains and disorders in professional sports. Challenge and answer to societal changes. Eur Arch Psychiatry Clin Neurosci. 2011;261:182.

11. Mistry AD, McCabe T, Currie A (Eds). Case studies in sports psychiatry. Cambridge, UK: Cambridge University Press; 2020.

12. Baron DA, Reardon CL, Baron SM. Clinical sports psychiatry: An international perspective. London: John Wiley and Sons; 2013.

13. Glick ID, Reardon CL, Stull T. Sports psychiatry: An update and the emerging role of the sports psychiatrist on the sports medicine team. Clin J Sport Med. 2020. https://doi.org/ 10.1097/JSM.0000000000000856

\section{History}

Received October 24, 2021

Accepted October 30, 2021

\section{Ira D. Glick, MD}

Department of Psychiatry and Behavioral Sciences

Stanford University School of Medicine

401 Quarry Road

Stanford, CA 94130

USA

iraglick@stanford.edu 